\title{
Acute Seizures Occurring in Association With SARS-CoV-2
}

\author{
Sean T. Hwang *, Ahmad A. Ballout, Usman Mirza, Anup N. Sonti, Arif Husain, \\ Claudia Kirsch, Ruben Kuzniecky and Souhel Najjar
}

Donald and Barbara Zucker School of Medicine at Hofstra/Northwell, North Shore University Hospital, Manhasset, NY, United States

Seizures are an infrequent and serious neurological complication of SARS-CoV-2 infection, with limited data describing the etiology and the clinical context in which these occur or the associated electrographic and imaging findings. This series details four cases of seizures occurring in patients with COVID-19 with distinct time points, underlying pathology, and proposed physiological mechanisms. An enhanced understanding of seizure manifestations in COVID-19 and their clinical course may allow for earlier detection and improved patient management.

Keywords: seizures, SARS-CoV-2, COVID-19, status epilepticus, neurological complication

\section{OPEN ACCESS}

Edited by:

Jorge Matias-Guiu,

Complutense University of

Madrid, Spain

Reviewed by:

Madihah Amima Hepburn, Cleveland Clinic, United States

Rocio García-Ramos,

Hospital Clínico San Carlos, Spain

*Correspondence:

Sean T. Hwang

shwang2@northwell.edu

Specialty section:

This article was submitted to

Neuroinfectious Diseases,

a section of the journal

Frontiers in Neurology

Received: 25 June 2020

Accepted: 29 September 2020

Published: 05 November 2020

Citation:

Hwang ST, Ballout AA, Mirza U,

Sonti AN, Husain A, Kirsch C, Kuzniecky R and Najjar S (2020) Acute Seizures Occurring in Association With

SARS-CoV-2.

Front. Neurol. 11:576329.

doi: 10.3389/fneur.2020.576329

\section{INTRODUCTION}

Coronavirus disease 2019 (COVID-19) associated with severe respiratory syndrome coronavirus 2 (SARS-CoV-2) presents with cough, fever, fatigue, and gastrointestinal symptoms. However, neurologic manifestations are reported in a third of patients and include dizziness, headaches, impaired consciousness, neuromuscular injury, changes in taste or smell, stroke, ataxia, or seizures (1).

Two early multicenter studies from China reported seizures in $0.47-0.66 \%$ of patients with COVID-19 $(1,2)$. Subsequent individual cases of seizures associated with COVID-19 were described, both as a presenting feature of COVID-19 and as a complication emerging later in the course of critically ill patients (3-12). Although seizures are uncommon, their occurrence is not unexpected given their association with other human coronavirus infections such as SARS-CoV and MERS reported in the literature $(13,14)$. There is increasing appreciation of the SARS-CoV-2 pathogenic mechanisms causing neurological injury and seizures.

This paper presents the clinical course and electroencephalographic (EEG) and neuroradiographic features of four cases of acute symptomatic seizure in the setting of SARSCOV-2 infection, highlighting distinct pathological mechanisms by which seizures may occur in the context of the unique and formidable illness of COVID-19.

\section{CASE PRESENTATIONS}

\section{Case 1}

A 48-year-old woman presented to urgent care complaining of fever, cough, vomiting, and malaise. Pneumonia was confirmed on chest X-ray, and she was prescribed with doxycycline and azithromycin. Three days later, she was brought in emergently for progressive confusion. She was febrile and tachypneic, with a blood pressure of $179 / 87 \mathrm{mmHg}$. She was alert, though aphasic, with impaired verbal output, naming, comprehension, and repetition. Babinski reflex was positive bilaterally. 
The patient then experienced three consecutive generalized tonic-clonic seizures (GTCS) associated with full body stiffening, dilated pupils, foaming at the mouth, and tongue bite up to 6 min apart, concerning for status epilepticus for which she was administered intravenous (IV) lorazepam and levetiracetam with resolution.

Initial laboratories were notable for mild transaminitis (AST $34 \mu / \mathrm{L}, \operatorname{ALT} 53 \mu / \mathrm{L}$ ) and elevated inflammatory markers (Ddimer $279 \mathrm{ng} / \mathrm{ml}$, ferritin $357 \mathrm{ng} / \mathrm{ml}$, and C-reactive protein 32 $\mathrm{mg} / \mathrm{ml}$ ). The toxicology result was negative. The chest X-ray result revealed bilateral interstitial infiltrates, and non-contrast computed tomography (CT) of the head was unrevealing. The patient was empirically treated for encephalitis with acyclovir and ceftriaxone. Lumbar puncture was traumatic, with the white blood cell count corrected to five per cubic millimeter and elevated protein of $125 \mathrm{mg} / \mathrm{dl}$. The results of cerebrospinal fluid (CSF) gram stain, culture, and polymerase chain reaction (PCR) for herpes were subsequently negative. The nasopharyngeal COVID-19 PCR test result was positive. CSF COVID-19 PCR was unavailable. Continuous EEG was performed postictally, showing severe generalized slowing but no epileptiform activity.

The patient remained febrile, tachycardic, and tachypneic, requiring intubation for hypoxemic respiratory failure. A 5day course of high-dose IV methylprednisolone was given for suspected COVID-19-associated central nervous system (CNS) involvement, as well hydroxychloroquine and a single 400-mg dose of tocilizumab. On day 13, the patient was extubated, with significant neurological improvement and resolution of her aphasia. MRI of the brain on day 19 demonstrated T2weighted (T2) and fluid-attenuated inversion recovery (FLAIR) hyperintensity in the medial temporal lobes bilaterally without restricted diffusion (Figure 1). The patient gradually improved and was discharged on day 25.

\section{Case 2}

A 29-year-old woman with iron deficiency anemia and menorrhagia presented after two GTCS with postictal confusion in the context of preceding fever, cough, and headache for 2 weeks. The initial vital signs were normal, except for tachycardia. While under observation, she suffered another GTCS with right gaze deviation, forced eye opening, tonic limb movements, and loss of awareness. This was aborted with IV lorazepam and levetiracetam. Postictal right-sided paralysis was noted.

The nasopharyngeal COVID-19 PCR test result was positive. Prolactin and D-dimer were notably elevated. Non-contrast CT of the head revealed edema, mass effect, and subcortical hemorrhages in the left temporal and parietal lobes as well as a hyperdense left transverse sigmoid sinus (Figure 1). A CT venogram confirmed left sigmoid and transverse cortical venous thrombosis (CVT), for which IV heparin was commenced. Pulmonary ground-glass opacities were noted on imaging.

EEG demonstrated asynchronous slowing and attenuation over the left hemisphere. CT of the head on day 2 showed evolving left temporal-parietal hemorrhagic infarction with midline shift and partial effacement of the right lateral and third ventricles. The patient developed bilateral abducens palsies and papilledema and was given acetazolamide for increased intracranial pressure. Mentation improved significantly by day 9 as she was able to respond to questions and moved all limbs antigravity, with a mild right facial droop. Hypercoagulable workup revealed anticardiolipin IgM antibodies. The patient was discharged on enoxaparin and levetiracetam.

\section{Case 3}

A 64-year-old woman with a history of hypertension, stage 4 chronic kidney disease, and non-insulin-dependent type 2 diabetes presented after two GTCS, lasting 2 min each, with postictal unresponsiveness. There had been 3 days of preceding
A

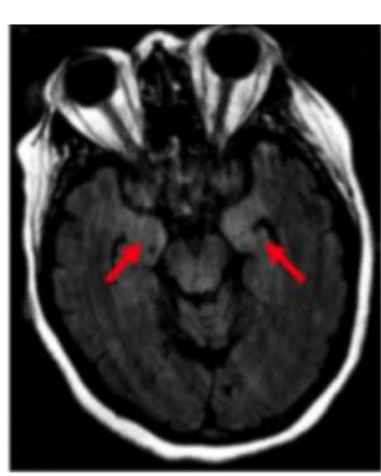

B

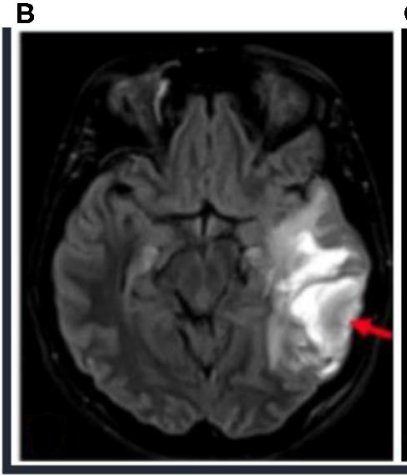

c

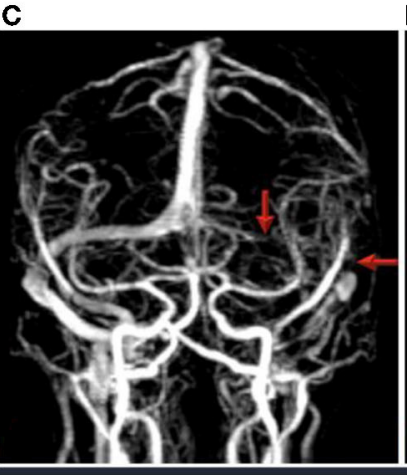

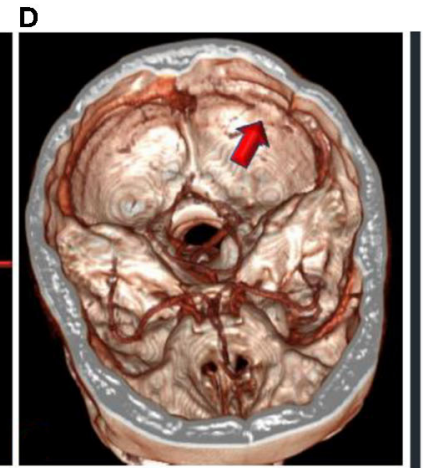

FIGURE 1 | (A) Case 1: 48-year-old, COVID-19-positive female with altered mental status; 3-T MRI axial FLAIR image (red arrows) of hyperintense FLAIR in the medial temporal lobe because of altered mental status and seizures, unable to hold still for scan, with resultant motion artifact. (B-D) Case 2: 29-year-old, COVID-19-positive female who presented with seizures. (B) 1.5-T MRI axial FLAIR (red arrow) of the left temporal lobe with hemorrhagic venous infarction, with the FLAIR hyperintensity consistent with edema and mass effect effacing the left ambient cistern. (C) 1.5-T MRI-time-of-flight MRI-with red arrows noting the absent flow void with venous thrombosis of the left transverse and sigmoid sinus and the left internal jugular vein. (D) CT venogram with the purple arrow demonstrating absent contrast enhancement and thrombosis of the left transverse and sigmoid sinus. 


\section{A}

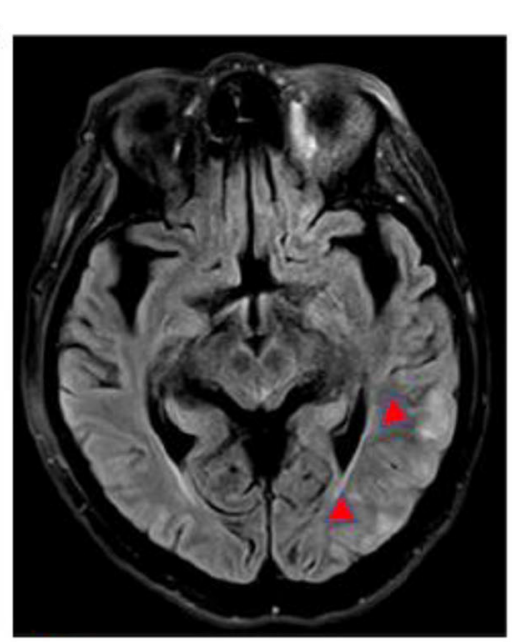

D

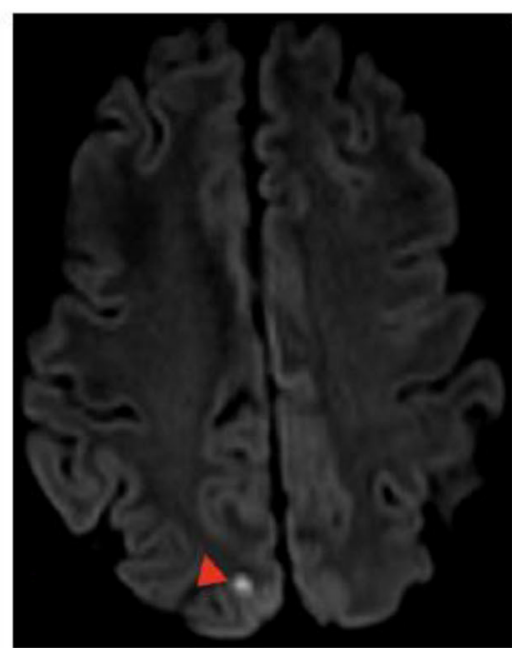

B

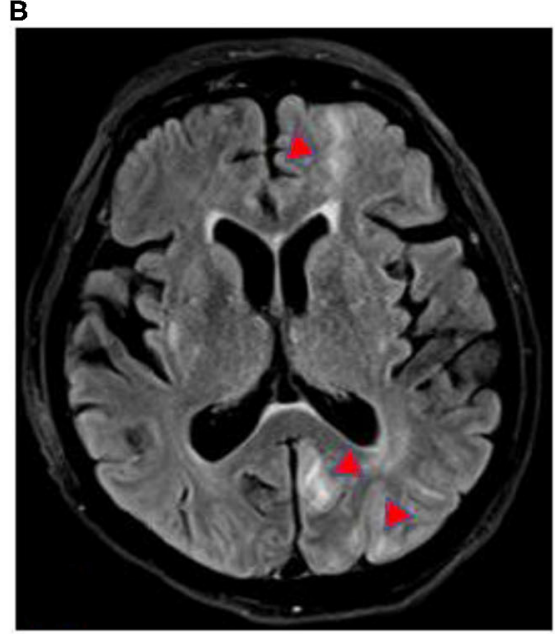

E

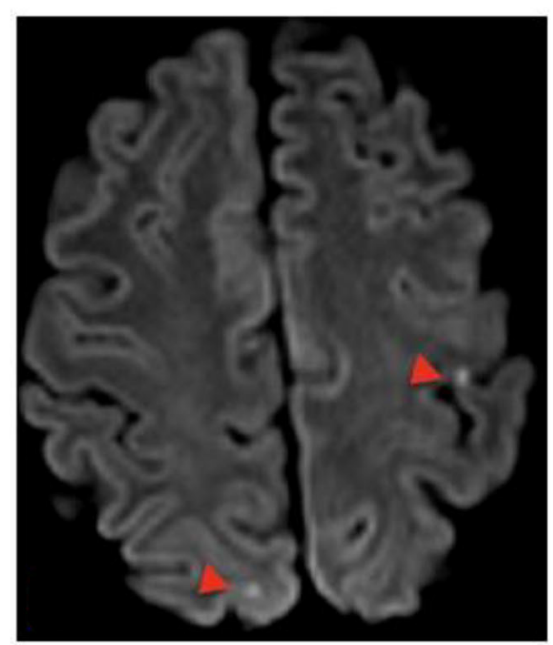

C

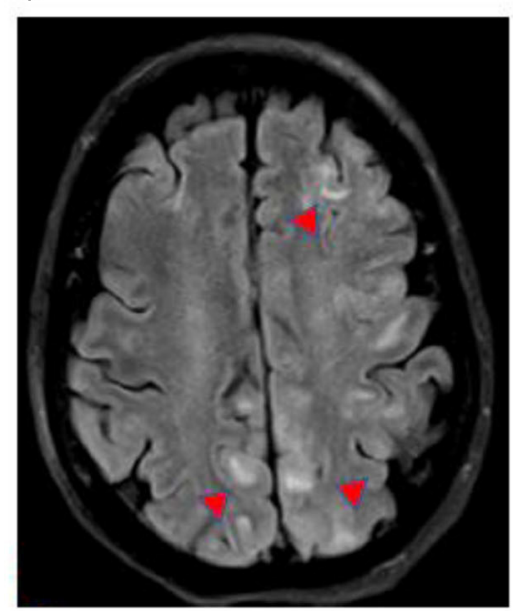

F

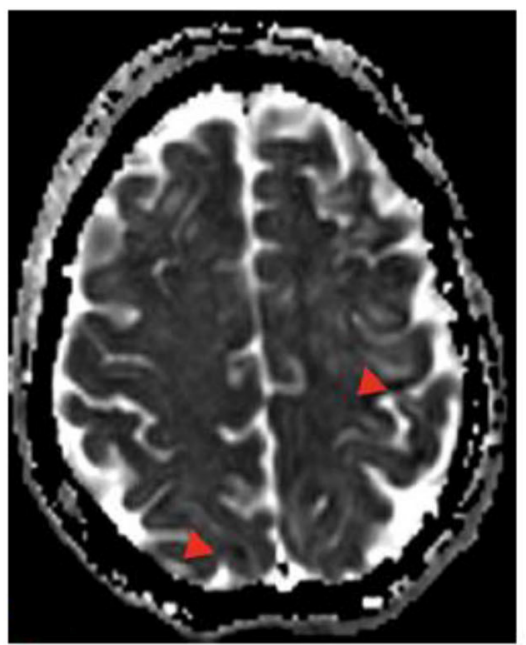

FIGURE 2 | (A-F) Case 3: 64-year-old COVID-positive female, axial 3-T MRI. (A-C) Axial FLAIR. (D,E) Axial DWI. (F) Axial apparent diffusion coefficient (ADC). FLAIR hyperintensity in the left was greater than that in the right cerebral hemispheres, with punctate DWI hyperintensity (red arrowheads) with ADC restricted diffusion. (F) Left precentral sulcus and right superior medial right parietal lobe, foci of FLAIR, DWI hyperintensity without restricted diffusion, and ADC T2-shine through, concerning posterior reversible encephalopathy in a patient with elevated blood pressure.

headache, vomiting, cough, and malaise. The patient was febrile, tachycardic, and tachypneic, with a blood pressure of 213/100 mmHG. She appeared obtunded with dilated and poorly responsive pupils, right gaze preference, and minimal withdrawal in all limbs to painful stimuli. Under observation, she suffered two additional GTCS and was treated with IV lorazepam, levetiracetam, and fosphenytoin with clinical cessation. Labetalol was given for hypertension.

The laboratory results were significant for thrombocytopenia $(77 \mathrm{~K} / \mu \mathrm{l})$, hyponatremia $(126 \mathrm{mmol} / \mathrm{L})$, elevated creatinine $(2.7$ $\mathrm{mg} / \mathrm{dl})$, blood urea nitrogen $(40 \mathrm{mg} / \mathrm{dl})$, and elevated ferritin. The non-contrast CT of the head and the chest radiograph were unrevealing. The CSF showed four nucleated cells with lymphocytic predominance, while gram stain, culture, and herpes testing were negative. The nasopharyngeal COVID-19 PCR was positive.

EEG was notable for generalized periodic discharges and slowing. Brain MRI without gadolinium, due to kidney dysfunction, showed punctate diffusion positive lesions in the left precentral sulcus and superior right medial parietal subcortical regions as well as patchy $\mathrm{T} 2$ prolongation in the left frontal, occipital, and bilateral parietal and cerebellar regions, most consistent with posterior reversible encephalopathy syndrome (PRES) (Figure 2).

The patient remained obtunded without seizures on continuous EEG, with steady improvement of her hyponatremia and blood pressure. Though PRES was of primary concern, a 5-day course of high-dose IV methylprednisolone was given due 
A

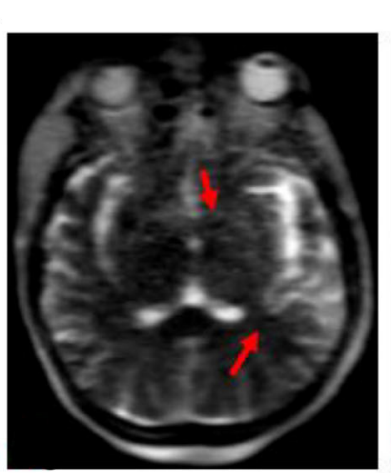

E

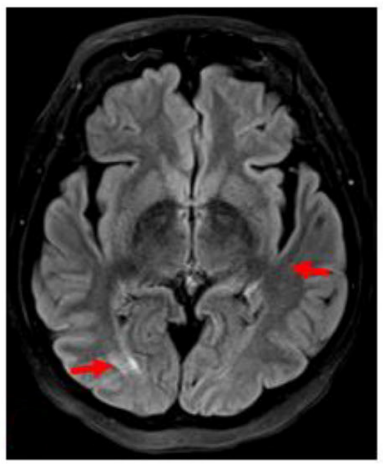

B

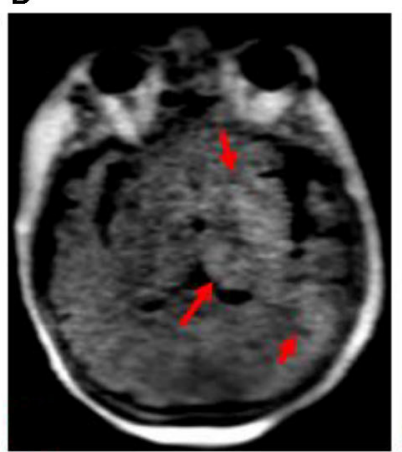

F

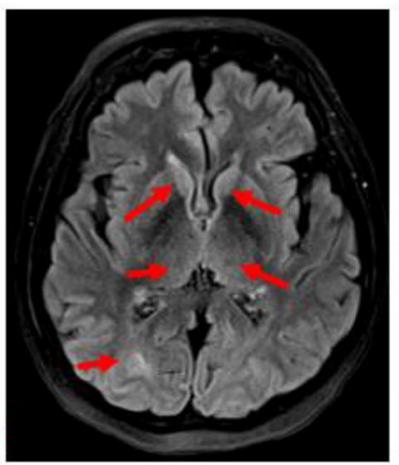

C

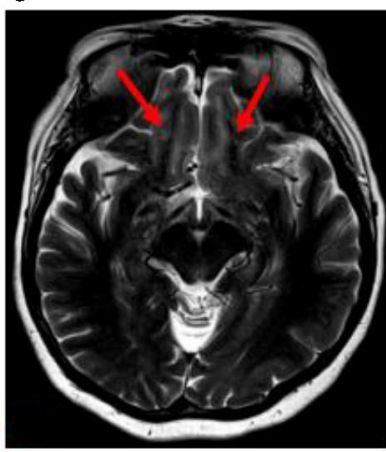

G

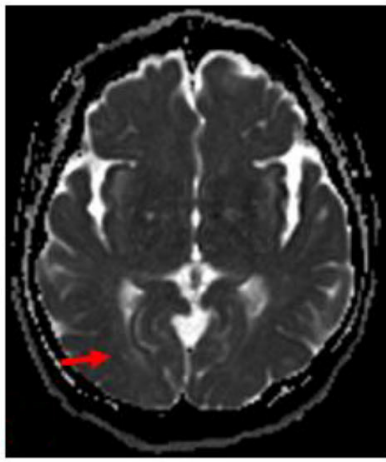

D

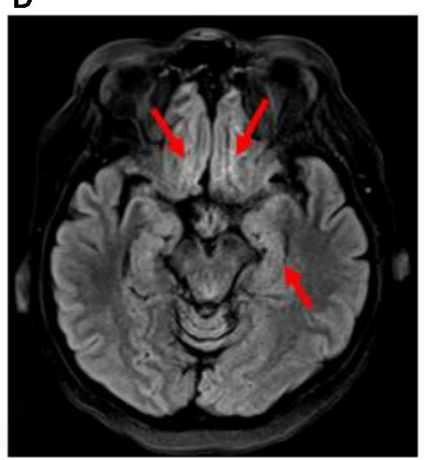

H

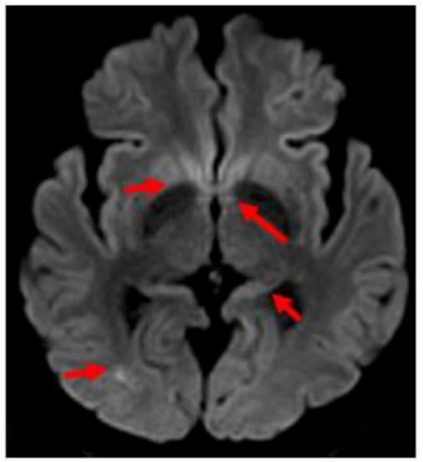

FIGURE 3 | (A-H) Case 4: 68-year-old, COVID-positive female. (A,B) Hyperfine 0.064-T portable MRI obtained 26 days after admission at the patient's bedside showing focal T2 and FLAIR hyperintensities (red arrows). (C-H) 3-T MRI obtained 39 days after admission. (C) Axial T2 and (D) axial FLAIR hyperintensities (red arrows): left subinsular cortex, lentiform nuclei, thalami, and left temporal lobe. (E,F) Axial FLAIR, (G) axial ADC, (H) axial DWI, T2, FLAIR, and DWI hyperintensities (red arrows): bilateral olfactory tracts, medial temporal lobes including hippocampal tails, caudate heads, fornices and posterior commissural fibers, right posterior lateral temporal lobe without restricted diffusion.

to consideration of inflammation-mediated seizures associated with COVID-19. The respiratory function was stabilized, and mentation improved by day 10 . On day 21 , she was discharged home at clinical baseline.

\section{Case 4}

A 68-year-old woman presented for diarrhea, fever, malaise, cough, and shortness of breath and found to be positive for COVID-19 3 days prior. She was febrile, tachycardic, tachypneic, and hypoxemic upon arrival. The chest X-ray showed bilateral lung infiltrates for which she was treated with azithromycin, ceftriaxone, and hydroxychloroquine. The patient decompensated, requiring intubation due to acute respiratory distress syndrome, and was given methylprednisolone and anakinra.

At 2 weeks into her course, the patient remained obtunded off of sedation. The head CT obtained on days 16 and 25 after admission demonstrated decreased attenuation in the left subinsular cortex and the thalamic region. EEG on day 17 showed severe generalized slowing. On day 26, portable 0.06-T MRI (Hyperfine) of the brain without contrast was performed, showing areas of T2 and FLAIR hyperintensity in the left thalamus and lentiform nuclei, though technically limited (Figure 3).

By day 27, she was extubated but remained confused, with the psychomotor slowed, and unable to follow commands. EEG on day 33 revealed unremitting high-amplitude centrotemporal sharp rhythmic $3-5-\mathrm{Hz}$ activity concerning non-convulsive status epilepticus (NCSE) (Figure 4). Clinical improvement was noted on the following day after the administration of IV lorazepam, levetiracetam, and lacosamide, with EEG transitioning to moderate background, slowing with intermittent left temporal sharp waves. The CSF results on day 36 were normal, including for COVID19 PCR. A follow-up 3-T contrast-enhanced brain MRI on day 39 showed T2, FLAIR, and diffusion-weighted imaging (DWI) hyperintensity without restricted diffusion along the bilateral olfactory tracts, caudate heads, posterior commissural fibers of the fornices, hippocampal tails, and right temporal lobe (Figure 3). By day 49, the patient was discharged to rehabilitation, alert and capable of conversation, though with moderate persistent cognitive and bilateral proximal weakness. 


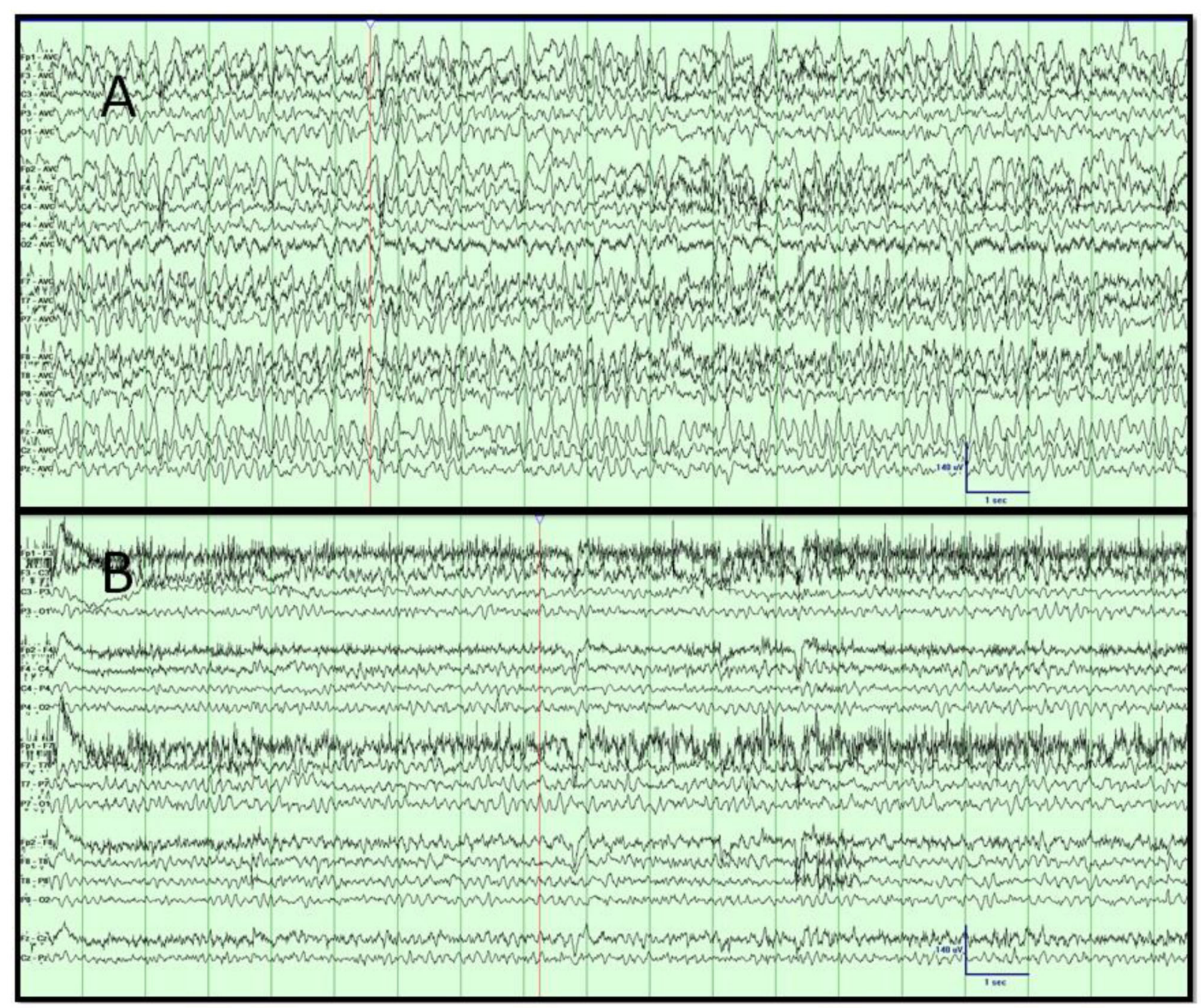

FIGURE 4 | (A,B) Case 4. Video EEG results. (A) Day 1 showing the high-amplitude rhythmic sharply contoured; intermixed 3- and 6-Hz activity concerning non-convulsive status epilepticus. (B) Day 2 with resolution of rhythmic slowing after the administration of lorazepam and levetiracetam, corresponding with improved mentation. Low-frequency filter, $1 \mathrm{~Hz}$; high-frequency filter, $70 \mathrm{~Hz}$; sensitivity, $7 \mu \mathrm{V} / \mathrm{mm}$; timebase, $30 \mathrm{~mm} / \mathrm{s}$.

Summaries of the pertinent clinical details of each case are presented in Table 1.

\section{DISCUSSION}

The cases above describe four scenarios of seizures occurring in association with COVID-19, illustrating the remarkable variety of neurological complications accompanying this disease. Seizures in this report may occur by differing mechanisms, including in the context of inflammatory changes in the brain as demonstrated by neuroimaging or vascular abnormalities related to the effects of SARS-CoV-2 on hypercoagulability and endothelial cell dysfunction.
In summary, the first case presented with seizures during the early acute phase of infection, with elevated inflammatory markers, and FLAIR changes in the temporal region on MRI indicative of focal inflammation (Figure 1A). Lumbar puncture did not reveal an evidence for encephalitis. In addition to antiseizure medications, the patient responded well to immunotherapy, with good neurological outcome, supporting a hypothesis of excessive innate immune activation. In case 2, the seizures resulted from acute CVT in the left transverse and sigmoid sinus, resulting in a left temporal lobe venous infarct (Figures 1B,D), highlighting a coagulopathic state associated with COVID-19. The seizures observed in case 3 manifested in the setting of a patient with elevated blood pressure and endstage kidney disease with PRES, raising concern for COVID-19 effects on endothelial cell function and vascular permeability. 
This patient demonstrated classic findings of increased T2, DWI, and FLAIR hyperintensity without restricted diffusion in the setting of elevated blood pressure (Figures 2A-F) and with a few punctate foci of restricted diffusion and ischemic change. The association of PRES as a neurologic complication of COVID-19 has been recently documented in the literature (15-18). The final patient was determined to have seizures later in her course, along with persistent altered mentation and radiographic findings suggestive of inflammatory changes and concern for immune-mediated necrotizing encephalopathy. Early portable magnetic resonance imaging using a Hyperfine MRI at the bedside, as the patient was too unstable to come down to the scanner (Figures 3A,B), demonstrated thalamic T2 and FLAIR hyperintensity, with follow-up conventional magnetic resonance imaging 2 weeks later showing bilateral hippocampal, forniceal, sub-insular, and orbitofrontal T2 and FLAIR abnormalities. Initiating antiseizure medications led to significant electrographic improvements and eventual delayed clinical improvement.

A few recent case reports are published in the literature describing acute symptomatic repetitive seizures in the setting of COVID-19. In an early report, the patient had positive CSF COVID-19 PCR and mesial temporal and lateral ventricular signal hyperintensities on MRI indicative of encephalitis (3). Additional rare cases may present with lymphocytic pleocytosis (19).

De novo focal seizures including status epilepticus in the absence of other medical comorbidities, neuroimaging, or lumbar puncture abnormalities are also described (7, 9-12, 20). New-onset seizures are reported in medically complex elderly patients with COVID-19; however, these were in the setting of multiorgan failure, metabolic derangements, and, in certain patients, superimposed sepsis or hypotension as complicating factors, and unfortunately, MRI or lumbar puncture results were often unavailable $(4,7,8)$. Seizure exacerbation and status epilepticus may also be exacerbated in patients with preexisting epilepsy and focal lesions, where COVID-19 infection may have lowered the seizure threshold $(5,21)$.

In a series of 214 consecutive patients with COVID-19 from China, only one individual experienced a convulsion, although 16 additional patients were reported with unspecified impaired consciousness (1). An additional retrospective multicenter study of 304 consecutive patients with COVID-19 reported only two cases of seizure-like events (2). One patient presented with facial deviation and acute anxiety, while the other experienced myoclonus with electrolyte imbalance. Eight additional patients were described as encephalopathic or comatose. Notably, in both publications, EEG was not performed due to concerns regarding infection control.

Although clinical seizures are infrequently encountered with COVID-19, NCSE may still need to be excluded by EEG in patients with unexplained altered mentation. Investigators recognize encephalopathy as a common occurrence among severely ill patients with COVID-19; however, concurrent EEG data are often unavailable, and further research is required to understand the true incidence of electrographic seizures in patients with SARS-CoV-2 infection. Relatively small cohorts of patients with COVID-19 and EEG are published to date, with the patients in these studies only undergoing routine duration or reduced montage EEG recording, for the reasons discussed above, and less frequently continuous EEG monitoring. Several authors observed sporadic epileptiform abnormalities and periodic patterns of concern, including generalized periodic discharges, along with more expected patterns of generalized slowing (22-26). Due to centers taking precautions to avoid transmission risk by reducing staffing and utilization of EEG, as well as obtaining imaging, cases of electrographic seizures and NCSE may be less likely to be diagnosed and adequately imaged. While the safety and risks of infection must be weighed carefully, patients may potentially benefit from the use of EEG and neuroimaging to recognize potentially treatable seizures.

The speculative mechanisms responsible for the neurological manifestations of SARS-CoV-2 are grouped broadly into direct viral invasion and indirect effects via systemic inflammation, coagulopathic states, endotheliopathy, and homeostatic disruptions, including metabolic derangements due to hypoxia and organ failure.

Given the genetic semblance between SARS-CoV and SARSCoV-2 and the shared manner of cellular entry via receptors for angiotensin-converting enzyme II (ACE2), neurotropism may be similar (27). Previous studies have demonstrated SARS$\mathrm{CoV}$ antigens and RNA within human neurons, supporting a hypothesis of neuroinvasion in SARS-CoV-2 (28). One proposed route of direct cell invasion involves receptors for ACE2, found on the surface of glia and endothelial cells, allowing for distinct ports of CNS entry $(29,30)$. CNS penetration may involve transaxonal transport along adjacent glia or hematogenous spread. Invasion via cells expressing ACE2 in the olfactory tract may lead to encephalitis associated with seizures and MRI signal changes indicative of edema and inflammation (3).

The upregulation of proinflammatory cytokines may also play a role in para-infectious immune-mediated neurological complications, such as demyelinating disease, acute necrotizing encephalopathy, or Guillain-Barre syndrome in COVID19 (31-36). Endothelial dysfunction and disruption of the integrity of the blood-brain barrier may result in cerebral antigen exposure and increased susceptibility to abnormal adaptive immunity. Similar neuroimmunological manifestations are reported with other coronaviruses, and seizures have been reported in this context (HCoV-OC43, SARS CoV, and MERS) (14, 30). These neurological presentations highlight the need for brain imaging in encephalopathic patients with COVID-19, particularly those with focal neurological deficits or seizures, which may reflect aberrant and excessive autoimmune phenomena. The neuroimaging findings in COVID-19 are extremely heterogenous and may vary based on the severity of infection (37). Immunotherapy, such as corticosteroids, targeted molecular therapies such as monoclonal antibodies, IV immunoglobulins, or convalescent plasma for patients with these manifestations may be potentially beneficial, though more systematic research is required (36, 38-40). During their course of treatment early on in the New York area pandemic, three patients in our series received methylprednisolone, two received hydroxychloroquine, one received tocilizumab, 
TABLE 1 | Case summaries.

\begin{tabular}{|c|c|c|c|c|c|c|c|c|c|}
\hline & $\begin{array}{l}\text { Clinical } \\
\text { presentation }\end{array}$ & $\begin{array}{l}\text { Pertinent } \\
\text { neurological } \\
\text { findings }\end{array}$ & $\begin{array}{l}\text { Seizure } \\
\text { semiology }\end{array}$ & Intubated & $\begin{array}{l}\text { Serum inflammatory } \\
\text { markers }\end{array}$ & CSF results & EEG findings & Radiological findings & $\begin{array}{l}\text { Possible } \\
\text { mechanism of } \\
\text { neuronal injury }\end{array}$ \\
\hline CASE \# 1 & $\begin{array}{l}\text { Fever, cough, } \\
\text { vomiting, malaise, } \\
\text { fever, tachycardia }\end{array}$ & $\begin{array}{l}\text { Global aphasia, } \\
\text { bilateral babinski } \\
\text { signs }\end{array}$ & GTCS & Yes & $\begin{array}{l}\text { ESR }=9 ; \\
\text { CRP = 32.6; } \\
\text { D-dimer = 279; } \\
\text { Fibrinogen }=352 ; \\
\text { Ferritin= } 357.4 ; \\
\text { Procalcitonin }=1.23\end{array}$ & $\begin{array}{l}\text { WBCs = 5/uL; } \\
\text { Protein = } 125 \mathrm{mg} / \mathrm{dL} ; \\
\text { Glucose = } 117 \mathrm{mg} / \mathrm{dL} ; \\
\text { Gram Stain, culture, } \\
\text { and HSV PCR } \\
\text { negative; } \\
\text { COVID-19 PCR } \\
\text { unavailable }\end{array}$ & $\begin{array}{l}\text { Severe generalized } \\
\text { slowing }\end{array}$ & $\begin{array}{l}\text { MRI brain: T2 } \\
\text { hyperintensities in the } \\
\text { medial temporal lobes }\end{array}$ & $\begin{array}{l}\text { Viral invasion vs. } \\
\text { secondary } \\
\text { inflammation }\end{array}$ \\
\hline CASE \# 2 & $\begin{array}{l}\text { Fever, cough, } \\
\text { dyspnea, } \\
\text { headache, } \\
\text { tachycardia }\end{array}$ & $\begin{array}{l}\text { Encephalopathy, } \\
\text { right hemiparesis }\end{array}$ & FBTCS & No & $\begin{array}{l}\text { ESR }=30 ; \\
\text { CRP = 111.7; } \\
\text { D-dimer = 2,876; } \\
\text { Fibrinogen =N/A } \\
\text { Ferritin= } 10.4 ; \\
\text { Procalcitonin }=0.06\end{array}$ & $\mathrm{~N} / \mathrm{A}$ & $\begin{array}{l}\text { Asynchronous } \\
\text { slowing and left } \\
\text { sided attenuation }\end{array}$ & $\begin{array}{l}\text { CT head: edema, mass } \\
\text { effect and subcortical } \\
\text { hemorrhages in the left } \\
\text { temporal and parietal lobes. } \\
\text { CTV: left sigmoid and } \\
\text { transverse cortical venous } \\
\text { thrombosis }\end{array}$ & CVT \\
\hline CASE \# 3 & $\begin{array}{l}\text { Headache, } \\
\text { vomiting, cough, } \\
\text { malaise, } \\
\text { hypertension }\end{array}$ & Encephalopathy & FBTCS & No & $\begin{array}{l}E S R=22 ; \\
C R P=<0.1 \\
\text { D-dimer =<150; } \\
\text { Fibrinogen = 588; } \\
\text { Ferritin= } 3,647 \\
\text { Procalcitonin }=0.45\end{array}$ & $\begin{array}{l}\text { WBCs = 4/uL; } \\
\text { Protein = } 43 \text { mg/dL; } \\
\text { Gram Stain, culture, } \\
\text { and HSV PCR } \\
\text { negative; } \\
\text { COVID-19 PCR } \\
\text { unavailable }\end{array}$ & GPDs & $\begin{array}{l}\text { MRI brain: multiple diffusion } \\
\text { positive lesions in the left } \\
\text { precentral sulcus and right } \\
\text { medial parietal regions; } \\
\text { patchy T2 prolongation in } \\
\text { the left frontal, occipital, and } \\
\text { bilateral parietal and } \\
\text { cerebellar regions }\end{array}$ & PRES \\
\hline CASE \# 4 & $\begin{array}{l}\text { Fever, diarrhea, } \\
\text { malaise, cough, } \\
\text { dyspnea }\end{array}$ & $\begin{array}{l}\text { Coma, subsequent } \\
\text { prolonged } \\
\text { encephalopathy }\end{array}$ & NCSE & Yes & $\begin{array}{l}\mathrm{ESR}=77 \\
\mathrm{CRP}=22.8 \\
\text { D-dimer }=1,137 \\
\text { Fibrinogen }=747 \\
\text { Ferritin= } 22.8 ; \\
\text { Procalcitonin }=0.29\end{array}$ & $\begin{array}{l}\text { WBCs }=1 / \mathrm{uL} ; \\
\text { Protein = } 30 \mathrm{mg} / \mathrm{dL} ; \\
\text { Glucose }=73 \mathrm{mg} / \mathrm{dL} ; \\
\text { Gram Stain, culture, } \\
\text { and HSV PCR } \\
\text { negative; } \\
\text { COVID-19 PCR } \\
\text { unavailable }\end{array}$ & $\begin{array}{l}\text { High amplitude } \\
\text { rhythmic } \\
\text { frontotemporal } \\
\text { theta, intermixed } \\
\text { left temporal sharp } \\
\text { waves }\end{array}$ & $\begin{array}{l}\text { MRI Brain }=T 2 \text {, FLAIR and } \\
\text { DWI hyperintensity without } \\
\text { restricted diffusion along the } \\
\text { bilateral olfactory tracts, } \\
\text { caudate heads, fornices, } \\
\text { hippocampi and right } \\
\text { temporal lobe }\end{array}$ & $\begin{array}{l}\text { Secondary } \\
\text { inflammation }\end{array}$ \\
\hline
\end{tabular}

Key: GTCS, Generalized tonic-clonic seizures; GPDs, Generalized periodic discharges; FBTCS, Focal to bilateral tonic-clonic seizures; NCSE, Non-convulsive status epilepticus; PRES, Posterior reversible encephalopathy syndrome; MRI, Magnetic resonance imaging; ESR, Erythrocyte sedimentation rate; CRP, C-Reactive protein; WBCs, White blood cells; HSV. Herpes simplex virus; PCR, Polymerase chain reaction; COVID-19, SARS-CoV-2; CVT, Cortical venous

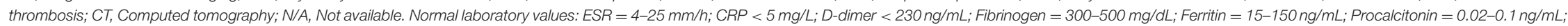
CSF Protein = 15-40 mg/dL; CSF Glucose = 40-70 mg/dL; CSF WBCs = 0-5 cell/uL. 
and one was administered anakinra. The treatments for COVID-19 remain highly variable at this time, and therapies specifically for neurological complications lack consensus. While potentially helpful for cytokine storming, data have subsequently called into question the early recommendations to utilize hydroxychloroquine in hospitalized COVID-19 patients due to safety concerns (36). While corticosteroids have significant antiinflammatory effects, caution is likewise advised to avoid the potential delay of viral clearance or other systemic complications, and timing and dosing of steroids may need to be considered carefully on a case-by-case basis for more severe cases of neuroinflammation (41). Research continues in support of drugs targeting cytokines via the IL-6 receptor, such as tocilizumab, and IL-1 receptor, such as anakinra (36).

Endothelial dysfunction may contribute to vascular events such as stroke (35). Viral cellular invasion via ACE2 expressed on the surface of glia, endothelial cells, myocardium, and arterial smooth muscle may predispose patients to thromboinflammation (42). Increases in systemic proinflammatory cytokines observed in COVID-19 such as IL-6, IL-10, and TNF- $\alpha$ are associated with hypercoagulability and microthrombi $(43,44)$. Elevated D-dimer levels are associated with thrombus formation and more severe infection and mortality (42). In one study, $6 \%$ of patients with COVID-19 were found to have acute strokes, theoretically predisposing them to a higher incidence of seizures (1). Nearly 3\% of non-COVID-19 adults with ischemic stroke suffer early seizures, while the rates of seizures in CVT are as high as $34 \%(45,46)$. CVT, as described in case 2, in COVID-19 has been reported, and given seizures as a common presenting feature, one should remain vigilant for this entity in the appropriate clinical context (47).

PRES in the setting of COVID-19 may similarly involve elevated cytokines due to systemic hyperinflammation, leading to endothelial activation and increased cerebrovascular permeability and edema. In the patient presented, underlying hypertension and renal disease may have been predisposing factors exacerbated by COVID-19, with additional cases of PRES in COVID-19 also reported $(15,16,18,48)$.

Acute seizures may also occur as a result of other systemic complications of COVID-19 resulting from hypoxia and inflammation, including multiorgan failure and associated metabolic disorders such as uremia, electrolyte abnormalities, and potential drug toxicity (14).

Seizures are a serious neurological manifestation of COVID19. Their occurrence may be a concerning indicator of direct

\section{REFERENCES}

1. Mao L, Jin H, Wang M, Hu Y, Chen S, He Q, et al. Neurologic manifestations of hospitalized patients with coronavirus disease 2019 in Wuhan, China. JAMA Neurol. (2020) 77:683-90. doi: 10.1001/jamaneurol.2020.1127

2. Lu L, Xiong W, Liu D, Liu J, Yang D, Li N, et al. New onset acute symptomatic seizure and risk factors in coronavirus disease 2019: a retrospective multicenter study. Epilepsia. (2020) 61:e49-53. doi: 10.1111/epi.16524

3. Moriguchi T, Harii N, Goto J, Harada D, Sugawara H, Takamino J, et al. A first case of meningitis/encephalitis associated with SARS-Coronavirus-2. Int J Infect Dis. (2020) 94:55-8. doi: 10.1016/j.ijid.2020.03.062 viral CNS involvement, autoimmune-mediated inflammation of the brain, neurovascular compromise, or cerebral autoregulatory abnormalities for which clinicians may need greater awareness of as potentially grave complications of SARS-CoV-2. Appropriate early diagnosis and treatment, with interventions such as antiseizure medications, immunotherapy, or modulation of blood pressure, may improve the outcome in these cases. Continued research is required to understand the true prevalence of electrographic seizures in a COVID-19-related neurological illness in a larger case series and to correlate those findings with radiographic abnormalities and effects on clinical outcome.

\section{DATA AVAILABILITY STATEMENT}

The original contributions presented in the study are included in the article/supplementary material, further inquiries can be directed to the corresponding author.

\section{ETHICS STATEMENT}

Written informed consent was obtained from the individual(s) for the publication of any potentially identifiable images or data included in this article.

\section{AUTHOR CONTRIBUTIONS}

$\mathrm{SH}, \mathrm{AB}, \mathrm{UM}, \mathrm{AS}$, and $\mathrm{AH}$ were responsible for the initial conception and draft of this manuscript. CK was responsible for neuroimaging descriptions and image preparation. CK, RK, and SN were responsible for guidance and editing of the manuscript. All authors contributed to the article and approved the submitted version.

\section{ACKNOWLEDGMENTS}

The Northwell Health Institutional Review Board approved this case series as minimal-risk research using data collected for routine clinical practice and waived the requirement for informed consent. We would like to acknowledge the contributions of the Northwell Health COVID-19 Research Consortium. The initial characteristics of 5,700 patients from Northwell are presented elsewhere (49). This case series provides in-depth laboratory, electroencephalographic, and radiographic results not presented in that article (Northwell COVID-19 Research Consortium record \#596).
4. Sohal S, Mossammat M. COVID-19 presenting with seizures. IDCases. (2020) 20:e00782. doi: 10.1016/j.idcr.2020.e00782

5. Vollono C, Rollo E, Romozzi M, Frisullo G, Servidei S, Borghetti A, et al. Focal status epilepticus as unique clinical feature of COVID19: a case report. Seizure. (2020) 78:109-12. doi: 10.1016/j.seizure.2020. 04.009

6. Asadi-Pooya AA. Zika virus-associated seizures. Seizure. (2016) 43:13. doi: 10.1016/j.seizure.2016.10.011

7. Chen W, Toprani S, Werbaneth K, Falco-Walter J. Status epilepticus and other EEG findings in patients with COVID-19: a case series. Seizure. (2020) 48:198-200. doi: 10.1016/j.seizure.2020.08.022 
8. Hepburn M, Mullaguri N, George P, Hantus S, Punia V, Bhimraj A, et al. acute symptomatic seizures in critically Ill Patients with COVID-19: is there an association? Neurocrit Care. (2020). doi: 10.1007/s12028-020-01006-1

9. Elgamasy S, Kamel MG, Ghozy S, Khalil A, Morra ME, Islam SMS. First case of focal epilepsy associated with SARS-coronavirus-2. J Med Virol. (2020) 92: 2238-42. doi: 10.1002/jmv.26113

10. Karimi N, Razavi AS, Rouhani N. Frequent convulsive seizures in an adult patient with COVID-19: a case report. Iran Red Crescent Med J. (2020) 22:e102828. doi: 10.5812/ircmj.102828

11. Balloy G, Leclair-Visonneau L, Péréon Y, Magot A, Peyre A, Mahé P-J, et al. Non-lesional status epilepticus in a patient with coronavirus disease 2019. Clin Neurophysiol. (2020) 131:2059-61. doi: 10.1016/j.clinph.2020.05.005

12. Somani S, Pati S, Gaston T, Chitlangia A, Agnihotri S. De novo status epilepticus in patients with COVID-19. Ann Clin Transl Neurol. (2020) 7:1240-4. doi: 10.1002/acn3.51071

13. Lau K-K, Yu W-C, Chu C-M, Lau S-T, Sheng B, Yuen K-Y. Possible central nervous system infection by SARS coronavirus. Emerging Infectious Diseases. (2004) 10:342-4. doi: 10.3201/eid1002.030638

14. Asadi-Pooya AA. Seizures associated with coronavirus infections. Seizure. (2020) 79:49-52. doi: 10.1016/j.seizure.2020.05.005

15. D'Amore F, Vinacci G, Agosti E, Cariddi LP, Terrana AV, Vizzari FA, et al. Pressing issues in COVID-19: probable cause to seize SARS-CoV-2 for its preferential involvement of posterior circulation manifesting as severe posterior reversible encephalopathy syndrome and posterior strokes. Am J Neuroradiol. (2020) 41:1800-1803. doi: 10.3174/ajnr.A6679

16. Parauda SC, Gao V, Gewirtz AN, Parikh NS, Merkler AE, Lantos J, et al. Posterior reversible encephalopathy syndrome in patients with COVID-19. J Neurol Sci. (2020) 416:117019. doi: 10.1016/j.jns.2020.117019

17. Kishfy L, Casasola M, Banankhah P, Parvez A, Jan YJ, Shenoy AM, et al. Posterior reversible encephalopathy syndrome (PRES) as a neurological association in severe Covid-19. I Neurol Sci. (2020) 414:116943. doi: 10.1016/j.jns.2020.116943

18. Franceschi AM, Ahmed O, Giliberto L, Castillo M. Hemorrhagic posterior reversible encephalopathy syndrome as a manifestation of COVID-19 infection. AJNR Am J Neuroradiol. (2020) 41:1173-6. doi: 10.3174/ajnr.A6595

19. Lyons S, O'Kelly B, Woods S, Rowan C, Brady D, Sheehan G, et al. Seizure with CSF lymphocytosis as a presenting feature of COVID-19 in an otherwise healthy young man. Seizure. (2020) 80:113-4. doi: 10.1016/j.seizure.2020.06.010

20. Fasano A, Cavallieri F, Canali E, Valzania F. First motor seizure as presenting symptom of SARS-CoV-2 infection. Neurol Sci. (2020) 41:16513. doi: 10.1007/s10072-020-04460-Z

21. Kadono Y, Nakamura Y, Ogawa Y, Yamamoto S, Kajikawa R, Nakajima Y, et al. A case of COVID-19 infection presenting with a seizure following severe brain edema. Seizure. (2020) 80:53-5. doi: 10.1016/j.seizure.2020.06.015

22. Vespignani H, Colas D, Lavin BS, Soufflet C, Maillard L, Pourcher V, et al. Report on electroencephalographic findings in critically Ill patients with COVID-19. Ann Neurol. (2020) 88:626-30. doi: 10.1002/ana.25814

23. Petrescu A-M, Taussig D, Bouilleret V. Electroencephalogram (EEG) in COVID-19: a systematic retrospective study. Neurophysiol Clin. (2020) 50:155-65. doi: 10.1016/j.neucli.2020.06.001

24. Galanopoulou AS, Ferastraoaru V, Correa DJ, Cherian K, Duberstein S, Gursky J, et al. EEG findings in acutely ill patients investigated for SARS-CoV2/COVID-19: a small case series preliminary report. Epilepsia Open. (2020) 5:314-24. doi: 10.1002/epi4.12399

25. Pasini E, Bisulli F, Volpi L, Minardi I, Tappatà M, Muccioli L, et al. EEG findings in COVID-19 related encephalopathy. Clin Neurophysiol. (2020) 131:2265-7. doi: 10.1016/j.clinph.2020.07.003

26. Vellieux G, Rouvel-Tallec A, Jaquet P, Grinea A, Sonneville R, d'Ortho M-P. COVID-19 associated encephalopathy: is there a specific EEG pattern? Clin Neurophysiol. (2020) 131:1928-30. doi: 10.1016/j.clinph.2020.06.005

27. Zhou P, Yang X-L, Wang X-G, Hu B, Zhang L, Zhang W, et al. A pneumonia outbreak associated with a new coronavirus of probable bat origin. Nature. (2020) 579:270-3. 10.1038/s41586-020-2012-7

28. Ding Y, He L, Zhang Q, Huang Z, Che X, Hou J, et al. Organ distribution of severe acute respiratory syndrome (SARS) associated coronavirus (SARS$\mathrm{CoV}$ ) in SARS patients: implications for pathogenesis and virus transmission pathways. J Pathol. (2004) 203:622-30. doi: 10.1002/path.1560
29. Baig AM, Khaleeq A, Ali U, Syeda H. Evidence of the COVID-19 virus targeting the CNS: Tissue distribution, host-virus interaction, and proposed neurotropic mechanisms. ACS Chem Neurosci. (2020) 11:9958. doi: 10.1021/acschemneuro.0c00122

30. Montalvan V, Lee J, Bueso T, De Toledo J, Rivas K. Neurological manifestations of COVID-19 and other coronavirus infections: a systematic review. Clin Neurol Neurosurg. (2020) 194:105921. doi: 10.1016/j.clineuro.2020.105921

31. Poyiadji N, Shahin G, Noujaim D, Stone M, Patel S, Griffith B. COVID 19-associated acute hemorrhagic necrotizing encephalopathy: CT and MRI features. Radiology. (2020) 296:E119-E120. doi: 10.1148/radiol.2020201187

32. Zanin L, Saraceno G, Panciani PP, Renisi G, Signorini L, Migliorati K, et al. SARS-CoV-2 can induce brain and spine demyelinating lesions. Acta Neurochir. (2020) 4:1-4. doi: 10.1007/s00701-020-04374-x

33. Alberti P, Beretta S, Piatti M, Karantzoulis A, Piatti ML, Santoro P, et al. Guillain-Barré syndrome related to COVID19 infection. Neurol Neuroimmunol Neuroinflamm. (2020) 7:e741. doi: 10.1212/NXI.0000000000000741

34. Toscano G, Palmerini F, Ravaglia S, Ruiz L, Invernizzi P, Cuzzoni MG, et al. Guillain-Barré syndrome associated with SARS-CoV-2. N Engl J Med. (2020) 382:2574-2576. doi: 10.1056/NEJMc2009191

35. Najjar S, Najjar A, Chong DJ, Pramanik BK, Kirsch C, Kuzniecky RI, et al. Central nervous system complications associated with SARS-CoV2 infection: integrative concepts of pathophysiology and case reports. $J$ Neuroinflammation. (2020) 17:231. doi: 10.1186/s12974-020-01896-0

36. Bhaskar S, Sinha A, Banach M, Mittoo S, Weissert R, Kass JS, et al. Cytokine storm in COVID-19-immunopathological mechanisms, clinical considerations, and therapeutic approaches: the reprogram consortium position paper. Front Immunol. (2020) 11:1648. doi: 10.3389/fimmu.2020.01648

37. Pan S, Chen WC, Baal JD, Sugrue LP. Neuroradiological findings in mild and severe COVID-19 infection. Acad Radiol. (2020). doi: 10.1016/j.acra.2020.08.026. [Epub ahead of print].

38. Joyner MJ, Bruno KA, Klassen SA, Kunze KL, Johnson PW, Lesser ER, et al. Safety update: COVID-19 convalescent plasma in 20,000 hospitalized patients. Mayo Clin Proc. (2020) 95:1888-97. doi: 10.1016/j.mayocp.2020.06.028

39. Xie Y, Cao S, Dong H, Li Q, Chen E, Zhang W, et al. Effect of regular intravenous immunoglobulin therapy on prognosis of severe pneumonia in patients with COVID-19. , J Infect. (2020) 81:31856. doi: 10.1016/j.jinf.2020.03.044

40. Mansourabadi AH, Sadeghalvad M, Mohammadi-Motlagh H-R, Rezaei N. The immune system as a target for therapy of SARS-CoV-2: a systematic review of the current immunotherapies for COVID-19. Life Sci. (2020) 258:118185. doi: 10.1016/j.lfs.2020.118185

41. Waterer GW, Rello J. Steroids and COVID-19: we need a precision approach, not one size fits all. Infect Dis Ther. (2020). doi: 10.1007/s40121-020-00338-x. [Epub ahead of print].

42. Connors JM, Levy JH. COVID-19 and its implications for thrombosis and anticoagulation. Blood. (2020) 135:2033-40. doi: 10.1182/blood.2020006000

43. Chen G, Wu D, Guo W, Cao Y, Huang D, Wang H, et al. Clinical and immunological features of severe and moderate coronavirus disease (2019). J Clin Invest. (2020) 130:2620-9. doi: 10.1172/JCI137244

44. Jose RJ, Manuel A. COVID-19 cytokine storm: the interplay between inflammation and coagulation. Lancet Respir Med. (2020) 8:e46-7. doi: 10.1016/S2213-2600(20)30216-2

45. Ferro JM, Correia M, Rosas MJ, Pinto AN, Neves G, Cerebral Venous Thrombosis Portuguese Collaborative Study Group. Seizures in cerebral vein and dural sinus thrombosis. Cerebrovasc Dis. (2003). 15:78-83. doi: 10.1159/000067133

46. Wang JZ, Vyas MV, Saposnik G, Burneo JG. Incidence and management of seizures after ischemic stroke: systematic review and meta-analysis. Neurology. (2017) 89:1220-8. doi: 10.1212/WNL.0000000000004407

47. Hemasian H, Ansari B. First case of Covid-19 presented with cerebral venous thrombosis: a rare and dreaded case. Revue Neurol. (2020) 176:5213. doi: 10.1016/j.neurol.2020.04.013

48. Kaya Y, Kara S, Akinci C, Kocaman AS. Transient cortical blindness in COVID-19 pneumonia; a PRES-like syndrome: case report. J Neurol Sci. (2020) 413:116858. doi: 10.1016/j.jns.2020.116858 
49. Richardson S, Hirsch JS, Narasimhan M, Crawford JM, McGinn T, Davidson $\mathrm{KW}$, et al. Presenting characteristics, comorbidities, and outcomes among 5700 patients hospitalized with COVID-19 in the New York City area. JAMA. (2020) 323:2052-9. doi: 10.1001/jama.2020.6775

Conflict of Interest: The authors declare that the research was conducted in the absence of any commercial or financial relationships that could be construed as a potential conflict of interest.
Copyright (C) 2020 Hwang, Ballout, Mirza, Sonti, Husain, Kirsch, Kuzniecky and Najjar. This is an open-access article distributed under the terms of the Creative Commons Attribution License (CC BY). The use, distribution or reproduction in other forums is permitted, provided the original author(s) and the copyright owner(s) are credited and that the original publication in this journal is cited, in accordance with accepted academic practice. No use, distribution or reproduction is permitted which does not comply with these terms. 